\title{
NOGUEIRA, Paulo Augusto de Souza. Narrativa e cultura popular no cristianismo primitivo. São Paulo: Paulus, 2018.
}

Daniel Salomão Silva ${ }^{1}$

Resumo: A obra desta resenha destaca uma hipótese de compreensão das primeiras comunidades cristãs a partir de suas formas de expressão, as quais possuem fortes conexões com a cultura popular do Mediterrâneo. Paulo Nogueira exercita esse método de análise nos Atos Apócrifos, exemplos de formas de cristianismo dos séculos II e III, que descrevem as ações dos apóstolos em algumas regiões do Império Romano. O autor propõe uma abordagem que não tenha a pretensão de encontrar a realidade por trás do texto, mas de compreender o pensamento dos primeiros cristãos, o que esperavam e em que acreditavam, a partir dos discursos registrados textualmente.

Palavras-chave: Cristianismo primitivo. Cultura popular. Helenismo. Ficcionalidade. Atos Apócrifos.

O professor Paulo Nogueira, doutor em Teologia pela Universidade deHeidelberg na Alemanha, tem se destacado já há alguns anos pela rica contribuição aos estudos dos cristianismos originários. $\mathrm{Na}$ obra resenhada, o autor propõe uma hipótese de compreensão das primeiras comunidades cristãs a partir de suas formas de expressão, as quais possuem fortes conexões com a cultura popular do Mediterrâneo. Nos Atos Apócrifos, escolhidos para análise mais detalhada, é possível observar essas interações.

Inicialmente, para o autor, os estudos dos cristianismos originários têm potencial crítico sobre a relação imbricada entre cristianismo e cultura ocidental na atualidade. Entretanto, quão distantes estão de nós os primeiros cristãos? Para interpretar esse passado não se pode "apenas estudar continuidades, rupturas, diferenças de contexto, processos e seus desenvolvimentos, mas engajar-se em complexos processos de tradução cultural" (NOGUEIRA, 2018, p. 15). Todavia, as informações sobre as primeiras comunidades cristãs são escassas e imprecisas.

Na obra analisada, o autor nos convida a um olhar para a literatura cristã apócrifa com estranhamento, aberto à surpresa e ao desconforto, na tentativa de algum distanciamento do que estamos acostumados ou das nossas expectativas. Os Atos Apócrifos se enquadram em um gênero literário que reúne elementos do gênero dos Atos

\footnotetext{
${ }^{1}$ Daniel Salomão Silva é bacharelem Ciências Humanas, graduando e mestrando em Ciência da Religião pela UFJF. Contato: salomaoime@yahoo.com.br.
} 
dos Apóstolos, dos evangelhos e da novela grega, com foco na ação missionária dos apóstolos na região do Mediterrâneo. Neles, os apóstolos realizam milagres e convertem pessoas da elite, terminando sempre martirizados. Nesta obra, Nogueira caminha entre o positivismo dos que pensam ser possível compreender plenamente o cristianismo primitivo apenas a partir do material canônico e os que negam essa possibilidade, pois essas fontes, fragmentárias e imaginativas, não permitem uma reconstrução social e cultural do período.

O autor busca delimitar o período do cristianismo primitivo. Definir seu início como a partir dos relatos dos evangelhos, em que se reconhece a tradição apostólica é inadequado, pois esses textos foram redigidos por testemunhos não apostólicos e por gerações posteriores. Por outro lado, os textos da patrística ${ }^{2}$ não podem ser considerados como do cristianismo primitivo devido a seu caráter dogmático e erudito. Estaria, enfim, delimitado entre o movimento de Jesus e o ano de 319, data do edito de Milão, quando deixaria de ser uma religião de resistência para se tornar prestigiada e poderosa.

O cristianismo começou como uma religião de intensa movimentação geográfica a partir da Palestina, chegando às comunidades judaicas da diáspora e aos não judeus. A ação missionária entre os gentios não foi exclusiva de Paulo de Tarso, mas de um grupo cujo modelo era o de um pregador "bilíngue, multicultural, itinerante, urbano, praticante de uma religião de conversão e de êxtase religioso" (NOGUEIRA, 2018, p. 33). Ser cristão significava adotar um sistema de linguagem, ser doutrinado em um conjunto de códigos, conhecer certos preceitos. Esses registros podem ser encontrados nos textos do Novo Testamento, mas também nos escritos dos Pais Apostólicos (não da patrística elaborada) e nos livros apócrifos, ou seja, não considerados canônicos, ainda que populares entre as comunidades cristãs mediterrâneas e usando os mesmos gêneros literários (judaicos e helenísticos). Sua importância está no fato de "terem sobrevivido num suporte que reflete uso quotidiano", de serem "testemunhas preciosas da prática de leitura e de cultivo do texto entre círculos amplos de cristãos, fora dos grandes centros de poder do Mediterrâneo" (NOGUEIRA, 2018, p. 37).

Partindo de uma crítica ao entendimento de Bultmann de que "a roupagem mítica da linguagem imped ia uma adequada apreciação" da mensagem bíblica (NOGUEIRA,

\footnotetext{
${ }^{2}$ Patrística é o período da história cristã, a proximadamente do início século II a o século VIII, que comporta os textos cristãos dos chamados Padres da Igreja, cujas teologias e filosofias foram de grande importância à ela boração do corpo doutrinário cristão.
} 
2018, p. 41), o autor propõe uma abordagem que não tenha a pretensão de encontrar a realidade por trás do texto, mas de compreender o pensamento dos primeiros cristãos, o que esperavam, em que acreditavam, a partir dos discursos registrados textualmente, pois “é em especial nas redes metafóricas, nas formas de narração e de articulação imaginativa que podemos estudar o cristianismo das origens" (NOGUEIRA, 2018, p. 44). Além disso, esse cristianismo originário deve ser compreendido como inserido em um universo cultural mais amplo, o do entorno do mar Mediterrâneo sob o domínio romano.

Outro paradigma questionado pelo autor é o de que há uma barreira entre a cultura das elites e a cultura popular. Na verdade, não se pode reconhecer uma unidade entre as classes sociais mais baixas (99\% da população), nem uma separação absoluta entre o pensamento da elite minoritária e essas classes. Entretanto, entendendo que a preocupação dos subalternos se direcionava principalmente à solução de problemas cotidianos, devemos reconhecer que os Pais da Igreja, já no século II, representavam "uma elite eclesial e intelectual que não reflete os temas, preocupações e as formas de expressão do cristianismo de caráter popular" (NOGUEIRA, 2018, p. 57).

Entendendo o cristianismo originário como imerso na cultura popular do Mediterrâneo, alguns pressupostos devem ser considerados como o de que essa cultura não anseia por coerência e caráter sistemático, mas é carregada de metáforas, narrativas, elementos fragmentários, ambíguos, contraditórios e grotescos; é de circulação ampla, não restrita a pequenos grupos, ainda que possa sofrer resistência deles e está em circularidade com a cultura da elite. Para Nogueira, mesmo que os cristãos se considerassem um povo separado, escolhido por Deus, que negasse quaisquer relações sincréticas com as crenças ao redor, não se pode admiti-los como um movimento isolado e sectário: ao contrário, para se articular na sociedade em que viviam, os cristãos precisavam conhecer seus valores, sua linguagem e as demais categorias de compreensão do mundo.

Em primeiro lugar, ser judeu ou cristão naquela época não era uma determinação étnica, mas cultural. Os primeiros cristãos eram oriundos tanto do judaísmo como das demais culturas mediterrânicas, logo já traziam de berço concepções diversas de mundo. Partindo disso, podiam usar modelos helenistas, por exemplo, na composição de seus textos. Além do mais, influências de outras fontes culturais, como papiros mágicos 
gregos, manuais de interpretação de sonhos, fábulas, lendas, amuletos etc., podem ser identificadas em materiais judaicos e cristãos do período.

Os Atos Apócrifos são exemplos de formas de cristianismo de muita antiguidade, dos séculos II e III, e descrevem as ações dos apóstolos em algumas regiões do Império Romano. Seu estudo tem sido mais valorizado nas últimas décadas, ainda que sejam considerados como fontes de um cristianismo exótico, isolado ou herético. Nogueira, ao contrário, entende que esses textos foram "produzidos por e representativos de cristãos comuns do segundo e terceiro séculos" (NOGUEIRA, 2018, p. 78). Através de sua análise, é possível conhecer os caminhos percorridos pelo cristianismo.

Entre esses textos, podemos destacar os que se referem à vida de Paulo de Tarso, como os Atos de Paulo, que incluem os Atos de Paulo de Tecla, Relatos de Viagens, Martírio em Éfeso, 3 a Carta aos Coríntios e Martírio de Paulo em Roma. Em sua análise, a perspectiva de que livros desse período podem ter sido desenvolvidos por uma coleta de diversas tradições é mais produtiva e apropriada que a perspectiva moderna de "autor". Algumas características interessantes podem ser observadas. Nos Atos de Paulo e Tecla, por exemplo, é possível encontrar a influência da novela grega, além de "uma ousada afirmação de autonomia e autoridade de mulheres no cristianismo paulino" (NOGUEIRA, 2018, p. 84). A presença de animais que falam, protegem ou são “convertidos" pelos apóstolos e outros personagens são também comuns nesses textos, como no Martírio em Éfeso, em que Paulo batiza um leão. Parcerias com animais ferozes fazem parte da cultura folclórica mediterrânea. Além disso, esses textos têm forte ênfase no miraculoso, ao mesmo tempo em que rejeitam práticas mágicas, ainda que algumas ações dos apóstolos se assemelhem a elas.

Outros textos destacados por Nogueira são os Atos de João. Como os demais Atos, revelam a preferência pelos locais públicos para a realização de milagres, "para que todos pudessem apreciar o poder dos milagreiros cristãos" (NOGUEIRA, 2018, p. 95). Mesmo disputas públicas com sacerdotes pagãos, com resultados violentos, à semelhança da disputa entre Elias e os sacerdotes de Baal (1Rs 18:20-40) podem ser encontradas. Em caminho diferente do percorrido pela tradicional exegese histórico-crítica, mais preocupada com a acuidade histórica na análise desses textos, é possível introduzir o conceito de ficcionalidade. Por esse ponto de vista, busca-se "estabelecer relações potenciais por meio da linguagem" (NOGUEIRA, 2018, p. 101), entendendo que a 
realidade apresentada é apenas uma possibilidade entre outras, mesmo que improváveis ou absurdas. Nogueira adota a hipótese de que "as narrativas do cristianismo primitivo faziam experimentos com o mundo, o invertiam, permitiam imaginar alternativas, davam voz e imaginação a grupos marginalizados" (NOGUEIRA, 2018, p. 104). Logo, indo além da preocupação com a realid ade histórica dos registros, é possível analisar os relatos e as memórias dos primeiros cristãos com mais empatia. Elementos imaginativos não devem ser encarados como roupagens descartáveis, mas como informações importantes para a análise do texto.

Os Atos de Felipe são bem heterogêneos, com relatos de viagem ao inferno, diálogos com demônios, curas, exorcismos, milagres e até transformação de animais em homens. Em sua análise, Nogueira destaca um bloco do livro em que Felipe, ao atravessar um deserto, depara-se com monstros. Na interpretação bíblica tradicional, monstros são sempre interpretados alegoricamente, como nas leituras do Apocalipse de João, em que são entendidos como referentes a Roma ou a elementos do culto imperial. No Novo Testamento aparecem "em apocalipses e nas fronteiras dos espaços geomíticos" (NOGUEIRA, 2018, p. 122). Todavia, por outro ponto de vista, essas imagens grotescas podem também traduzir ansied ades, desejos ou desconfortos dos cristãos, logo, merecem atenção do pesquisador que busca compreender a cultura do cristianismo primitivo e seus dilemas.

Essas formas e narrativas populares dos cristianismos originários resistiram "à emulação ord enada e passiva de formas de narrar das elites” (NOGUEIRA, 2018, p. 139) e mantiveram linguagens diferentes dos modelos jurídicos e filosóficos das camadas superiores. Por esse motivo podem revelar aspectos diferentes dos já buscados pelos métodos tradicionais.

Entendemos que a obra é de grande importância como introdução à leitura dos Atos Apócrifos e dos apócrifos em geral ao destacar sua linguagem eventualmente "estranha", se comparada ao material canônico. A leitura exegética tradicional, apegada aos dados possivelmente históricos dos textos, deixa de lado narrativas e aspectos fantásticos que abundam nestas obras e que podem revelar pistas sobre o pensamento de seus autores e usuários. Afinal, por que essas comunidades “inventariam” essas histórias? Com qual intenção? Essas e outras perguntas merecem atenção do pesquisad or e a obra de Paulo Nogueira é um bom ponto de partida para esta tarefa. 